\title{
A role for TET2 in parathyroid carcinoma
}

\author{
Elham Barazeghi', Anthony J Gill2, Stan Sidhu3,4, Olov Norlén',3,4, Roberto Dina5, \\ F Fausto Palazzo6, Per Hellman', Peter Stålberg',* and Gunnar Westin 1,*
}

\author{
'Department of Surgical Sciences, Endocrine Unit, Rudbeck Laboratory, Uppsala University, Uppsala, Sweden \\ ${ }^{2}$ Cancer Diagnosis and Pathology Research Group, Kolling Institute of Medical Research, St Leonards, \\ New South Wales, Australia \\ 3Department of Surgery, Royal North Shore Hospital, St Leonards, New South Wales, Australia \\ 4 University of Sydney, Sydney, New South Wales, Australia \\ ${ }^{5}$ Department of Histopathology, Hammersmith Hospital, Imperial College, London, UK \\ ${ }^{6}$ Department of Endocrine Surgery, Hammersmith Hospital, Imperial College, London, UK \\ *(P Stålberg and G Westin contributed equally to this work)
}

Correspondence

should be addressed to P Stålberg or G Westin Email peter.stalberg@surgsci.uu.se or gunnar.westin@surgsci. uu.se

\footnotetext{
Abstract

Primary hyperparathyroidism (pHPT) is rarely caused by parathyroid carcinoma (PC, $<1-5 \%$ of pHPT cases). The TET proteins oxidize the epigenetic mark 5 -methylcytosine to 5 -hydroxymethylcytosine $(5 \mathrm{hmC})$ and inactivation by mutation or epigenetic deregulation of TET1 and TET2 play important roles in various cancers. Recently, we found that $5 \mathrm{hmC}$ was severely reduced in all of the analyzed PCs and with deranged expression of TET1 for the majority of PCs. Here, we have examined the expression of the TET2 protein in 15 hmC-negative PCs from patients who had local invasion or metastases. Cell growth and cell migratory roles for TET2 as well as epigenetic deregulated expression were addressed. Immunohistochemistry revealed very low/undetectable expression of TET2 in all PCs and verified for two PCs that were available for western blotting analysis. Knockdown of TET2 in the parathyroid cell line sHPT-1 resulted in increased cell growth and increased cell migration. DNA sequencing of TET2 in PCs revealed two common variants and no obvious inactivating mutations. Quantitative bisulfite pyrosequencing analysis of the TET2 promoter CpG island revealed higher CpG methylation level in the PCs compared to that in normal tissues and treatment of a PC primary cell culture with the DNA methylation inhibitor 5-aza-2'-deoxycytidine caused increased expression of the methylated TET2 gene. Hence, the data suggest that deregulated expression of TET2 by DNA hypermethylation may contribute to the aberrantly low level of $5 \mathrm{hmC}$ in PCs and further that TET2 plays a cell growth and cell migratory regulatory role and may constitute a parathyroid tumor suppressor gene.
}
Key Words
- 5-hydroxymethylcytosine
- TET2
- primary hyperparathyroidism
- parathyroid carcinoma
- promoter hypermethylation
- tumor suppressor

Endocrine-Related Cancer (2017) 24, 329-338

\section{Introduction}

Parathyroid carcinoma (PC) is a slow-growing and rare parathyroid disease associated with highly elevated parathyroid hormone levels and hypercalcemia. PC occurs in less than 1 to $<5 \%$ of primary hyperparathyroidism
(pHPT) cases with a high tendency of local recurrence, and current diagnosis relies on demonstration of invasive growth patterns and metastasis. CDC73/HRPT2 somatic mutations, encoding parafibromin, are common in 
PCs (approximately 70\%), and parafibromin-negative immunostaining has been suggested as a marker for PC, although some studies reported this to be less useful (Tan et al. 2004, Iacobone et al. 2005, DeLellis et al. 2008, Sharretts \& Simonds 2010, Guarnieri et al. 2012, Cetani et al. 2013, Gill 2014, Westin 2016). Lost expression of the APC tumor suppressor gene has been suggested to occur in PCs through epigenetic inactivation by DNA methylation of the APC promoter region (Svedlund et al. 2010). Recently, we have reported very low or undetectable level of 5-hydroxymethylcytosine (5hmC) in PCs and suggested that $5 \mathrm{hmC}$ could present a potential marker to distinguish PC from parathyroid adenoma (Barazeghi et al. 2016).

The epigenetic mark $5 \mathrm{hmC}$ is a covalent cytosine modification that is commonly and severely reduced in various types of cancers, including hematological malignancies and solid tumors of colorectal, prostate and breast tissues. Discovery of the ten-eleven translocation (TET) family of proteins (TET1/2/3), which oxidizes 5 -methylcytosine to $5 \mathrm{hmC}$ and further on to 5 -formyl and 5-carboxylcytosine, suggested a novel mechanism to regulate DNA methylation through the active demethylation pathway with $5 \mathrm{hmC}$ acting both as an intermediate and a unique epigenetic mark in gene expression regulation (Tahiliani et al. 2009, Ito et al. 2010). Decreased levels of $5 \mathrm{hmC}$ in a wide variety of cancers compared with normal tissues has been shown to be associated with downregulation of TET gene expression (Haffner et al. 2011, Kudo et al. 2012, Lian et al. 2012, Huang \& Rao 2014, Barazeghi et al. 2016, Rasmussen \& Helin 2016).

TET2 has been found frequently mutated in different types of hematological malignancies, supporting a tumor suppressor role of TET2 in myeloid cancers (AbdelWahab et al. 2009, Jankowska et al. 2009, Ko et al. 2010). In solid tumors, however, mutations in the TET genes were found with relatively low frequency, suggesting that there are other mechanisms involved in aberrant expression of TET proteins (Kan et al. 2010, Scourzic et al. 2015). Epigenetic alterations such as DNA methylation of gene regulatory regions may contribute to TET2 silencing. Promoter hypermethylation has been noted in a few studies; in multiple sclerosis, it was associated with decreased expression of TET2 and lower level of $5 \mathrm{hmC}$ (Calabrese et al. 2014). Moreover, hypermethylation has been shown to occur with low frequency in pediatric acute myeloid lymphoblastic leukemia, Ph-negative myeloperative neoplasms, and low-grade diffuse gliomas (Chim et al. 2010, Kim et al. 2011, Musialik et al. 2014).
TET1 was recently shown by us to be involved in PC (Barazeghi et al. 2016) and here we present data for the first time suggesting deregulated expression of TET2 by promoter hypermethylation. In vitro cell culture experiments further support a cell growth regulatory and cell migratory role of TET2 in parathyroid cells and function as a possible tumor suppressor gene in parathyroid tissue.

\section{Materials and methods}

\section{Tissue specimens}

PCs $(n=18)$ from 16 patients who had unequivocal local invasion and/or metastases were acquired from patients diagnosed and operated on in clinical routine at the Uppsala University Hospital, Uppsala, Sweden, Department of Surgery, Royal North Shore Hospital, St Leonards, Australia and Hammersmith Hospital, London, United Kingdom. PC \#1-11 corresponded to PC \#1-11 and PC \#12-15 corresponded to PC \#14-17 in Barazeghi and coworkers (2016). The clinical data and results from immunohistochemistry analysis of parafibromin are shown in Supplementary Table 1 (see section on supplementary data given at the end of this article). Apparent normal parathyroid tissue $(n=6)$ was obtained as normal parathyroid gland biopsies inadvertently removed from four patients subjected to parathyroidectomy and from two patients subjected to thyroidectomy. These six specimens were used for comparisons with parathyroid tumor tissues. It may be that the epigenetic status of these specimens does not fully represent that of normal parathyroid glands in healthy individuals. Informed consent and approval were obtained from the Uppsala local ethical committee, the Northern Sydney Local Health District Human Research Ethics Committee and the Imperial College Research Ethics Committee, London.

\section{Immunostainings}

Immunohistochemistry: Paraffin-embedded tissue sections were deparaffinized with xylene and rehydrated through descending alcohol concentrations and distilled water. Sections were treated with 3\% hydrogen peroxide and heated in citrate buffer $\mathrm{pH} 6.0$, for $10 \mathrm{~min}$ with microwave at $800 \mathrm{~W}$ power, and then $20 \mathrm{~min}$ at $450 \mathrm{~W}$ power. The sections then were treated with normal goat serum and the rabbit polyclonal anti-TET2 antibody (21207-1-AP, Proteintech Group, Manchester, UK).

Published by Bioscientifica Ltd. 
The sections were washed 3 times with PBS, and then incubated with a proper secondary antibody and $\mathrm{ABC}$ complex. DAB (3,3'-diaminobenzidine) was used for visualization. Frozen sections of apparent normal parathyroid tissues (N2 and N3) were fixed in formalin and stained as described above. sHPT- 1 cells on chamber slides were first fixed in formalin and then incubated with ice-cold $70 \%$ alcohol for $20 \mathrm{~min}$. Then, the slides were treated with goat polyclonal anti-PTH antibody (sc-9678; Santa Cruz Biotechnology), and then washed 3 times with PBS, followed by incubation with a proper secondary antibody and ABC complex. 3-Amino-9-ethyl carbazole (AEC) was used for visualization.

Immunofluorescence: sHPT-1 cells were treated as mentioned above. After incubation with the goat polyclonal anti-PTH antibody, the slides were washed 3 times with PBS (0.05\% Tween 20), followed by incubation with a proper fluorescence secondary antibody (Alexa 488, Life Technologies). Slides were washed again and mounted with VECTASHIELD with DAPI (Vector Laboratories, Inc., Burlingame, CA, USA).

\section{DNA and RNA extraction}

Total DNA from FFPE tissue was extracted using QIAamp DNA FFPE tissue kit (Qiagen $\mathrm{GmbH}$ ) and from frozen tissue or blood using DNeasy Blood and tissue kit (Qiagen). DNA-free total RNA was extracted using RNeasy Plus Mini kit (Qiagen) according to manufacturer's instructions.

\section{Bisulfite treatment and pyrosequencing}

Eleven PCs and 4 normal were included in the analysis. Bisulfite treatment was performed on 500 ng of DNA using the EpiTect bisulfite kit (Qiagen) according to the manufacturer's instructions. To cover $29 \mathrm{CpG}$ sites in the TET2 promoter region, 3 PCRs were performed before pyrosequencing. PCR and sequencing primers are listed in Supplementary Table 2. The PCR included MyTaq HS Mix (Bioline USA Inc., Taunton, USA), 10 pmol of each primer and bisulfite-treated DNA as template. Touchdown PCR was performed with initial denaturation at $95^{\circ} \mathrm{C}$ for $2 \mathrm{~min}$, followed by 10 cycles of $95^{\circ} \mathrm{C}, 15 \mathrm{~s}$; annealing temperature step-downs every cycle of $0.5^{\circ} \mathrm{C}$ (from $60^{\circ} \mathrm{C}$ to $56^{\circ} \mathrm{C}$ ); $72^{\circ} \mathrm{C}$, 20 s; the annealing temperature for the final 40 cycles was $56^{\circ} \mathrm{C}$ followed by denaturation and extension phases as above. Pyrosequencing was done using $20 \mu \mathrm{L}$ PCR product with the PyroMark Q24 system (Qiagen) according to manufacturer's instructions.

\section{PCR amplification and DNA sequencing}

TET2 coding exons 3-11 in nine PCs from seven patients and exon 11 in additional five PCs and in one blood sample were amplified by PCR amplification, followed by Sanger sequencing (Genewiz, Beckman Coulter Genomics, Takeley, UK). Fragments were aligned to the TET2 reference sequence (Genome Reference Consortium Human Build 38, GRCh38) and analyzed. Sequencing primers are available upon request.

\section{Cell culture, transfection and drug treatment}

sHPT-1 parathyroid tumor cells (Björklund et al. 2007) were distributed onto $35-\mathrm{mm}$ dishes $\left(2 \times 10^{5}\right)$ in DMEM/10\% fetal bovine serum (Sigma) and transfected with $1 \mu \mathrm{g}$ TET2 clustered regularly interspaced short palindromic repeats (CRISPRs) double nickase plasmid (sc-400545-NIC) or control double nickase plasmid (sc-437281). Santa Cruz Biotechnology) using FuGENE 6 transfection reagent (Promega), according to manufacturer's instructions. Successful transfection was determined by real-time quantitative RT-PCR and western blotting. Preparation of PC cells directly after surgery and treatment with 5-aza-2'-deoxycytidine (Aza) has been described (Svedlund et al. 2010).

\section{Colony formation and proliferation assays}

For colony formation assay, sHPT-1 cells transfected in triplicates, and a fresh medium with $0.5 \mu \mathrm{g} / \mathrm{mL}$ puromycin (Invivogen, Toulouse, France) was added after $24 \mathrm{~h}$ and refreshed every $72 \mathrm{~h}$. After 14 days selection in puromycin, the cells were fixed with 10\% acetic acid/10\% methanol and stained with $0.4 \%$ crystal violet, and visible colonies were counted. Three biological replicates of the experiment were performed. The CyQUANT cell proliferation assay kit (Invitrogen, Thermo Fisher Scientific) was used to assess the effect of TET2 downregulation on the proliferation of sHPT-1 cells according to manufacturer's protocol. sHPT-1 cells were transfected in triplicates and after 2 weeks under selection, $25 \mathrm{k}$ cells per well were seeded in a 96-well plate in six replicates. After $24 \mathrm{~h}$, the media was removed and the plate was frozen. For the assay, cells were lysed and stained with CyQuant GR dye solution. Infinite 200 PRO (TECAN) plate reader was used to measure fluorescence intensity at $480 / 520 \mathrm{~nm}$. A linear relationship was obtained for the cell number standard curve according to the fluorescence measurement.

Published by Bioscientifica Ltd. 


\section{Cell migration and invasion assays}

Migration and invasion capacity was measured in vitro using Cytoselect 96-well cell migration assay (CBA-106; Cell Biolabs Inc., San Diego, CA, USA) and Cytoselect 96-well cell invasion assay (basement membrane, CBA112) according to manufacturer's protocols in the presence and absence of $6 \mu \mathrm{g} / \mathrm{mL}$ mitomycin C (Sigma-Aldrich) to block proliferation. sHPT-1 cells were transfected in triplicates and selected as mentioned above. After 14 days under selection, cells were seeded in six replicates in reduced serum media (Opti-MEM) and added to the upper chambers of the 96-well plates at the density of $10 \mathrm{k}$ per well, and complete media (10\% fetal bovine serum) to the bottom chambers as attractant. After 24-h incubation, migrating/invading cells were detached from underside of the membrane and lysed and stained with CyQuant GR dye solution. Fluorescence intensity was measured at 480/520 nm using Infinite 200 PRO plate reader (TECAN, Männedorf, Switzerland). For the migration assay, three biological replicates were performed and one for the invasion assay.

\section{Western blotting analysis}

Protein extracts prepared using Cytobuster Protein Extract Reagent (Merck Millipore) with complete protease inhibitor cocktail (Roche Diagnostics Scandinavia AB). Rabbit polyclonal anti-TET2 (21207-1-AP, Proteintech Group) and goat polyclonal anti-Actin (sc-1616; Santa Cruz Biotechnology) were used. After incubation with the appropriate secondary antibody, bands were visualized using the enhanced chemiluminescence system (GE Healthcare Bio-Sciences).

\section{Quantitative RT-PCR}

Total RNA was treated with DNase I using TURBO DNAfree kit (Life Technologies Corporation, Thermo Fisher Scientific), and successful treatment was established by PCR analysis. cDNA synthesis was performed using the First-Strand cDNA Synthesis kit (Fermentas, Thermo Fisher Scientific) according to the manufacturer's instructions. Quantitative RT-PCR was performed on StepOnePlus Real-Time PCR systems (Life Technologies Corporation) using TaqMan gene expression Master Mix and assays for TET2 (Hs00325999_m1 and Hs00289469_ m1, PTH (Hs00757710_g1), CASR (Hs01047795_m1), GCM2 (Hs00171702_m1), and GAPDH (Hs02758991_g1) transcripts. Each cDNA sample was analyzed in triplicate.

\section{Statistical analysis}

Unpaired and paired t-tests were used for statistical analysis and all data presented mean \pm S.E.M. $P<0.05$ was considered significant. Statistical analysis was performed using R version 3.2.3 (2015-12-10).

\section{Results}

\section{Expression of TET2 is aberrantly reduced in PCs}

Recently, we showed that PCs stained negatively for $5 \mathrm{hmC}$ by immunohistochemistry, thus indicating very low or undetectable level of $5 \mathrm{hmC}$ in PCs. This was accompanied by undetectable or aberrant expression patterns for TET1 in 13 of 17 analyzed tumors (Barazeghi et al. 2016). Like TET1, TET2 is also responsible for conversion of $5 \mathrm{mC}$ to $5 \mathrm{hmC}$ (Ito et al. 2010). Immunohistochemical analysis was therefore performed to see whether TET2 expression was altered in PCs in comparison to normal parathyroid tissues and kidneys, included as positive controls. Fifteen PCs from 13 patients were included and the analysis showed very low to undetectable TET2 staining for all the PCs compared to that of normal parathyroid tissue and kidneys, in which both showed clear positive nuclear staining (Fig. 1A). In agreement, western blotting analysis revealed undetectable levels of TET2 expression in two of the PCs that were also available as frozen tissues, further supporting TET2 downregulation in PCs (Fig. 1B).

\section{Reduced expression of TET2 caused increased parathyroid tumor cell growth and migration}

The human parathyroid tumor cell line sHPT-1 was used to investigate whether TET2 could play a growth regulatory role and have an impact on cell migration. This cell line was established from a hyperplastic parathyroid gland removed at operation from a patient with secondary hyperparathyroidism due to renal insufficiency, and clearly expressed TET2 (Fig. 1B). Efficient knockout of TET2 mRNA and protein expression was obtained by transfection of TET2 CRISPR double nickase plasmids (Fig. 2A), rather than TET2 siRNAs (not shown). Under these knockout conditions in a colony-forming assay, a significantly increased number and size of sHPT-1 cell colonies appeared when compared to empty vector transfected control cells (Fig. 2B and C). This finding was further supported by the increased cell viability observed after transfection (Fig. 2D and Supplementary Fig. 1).

Published by Bioscientifica Ltd. 
A $\mathrm{PCl}$

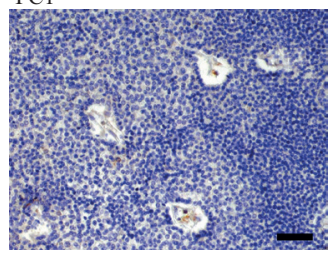

PC5

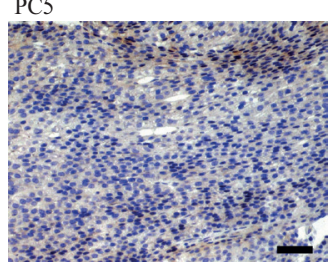

PC9

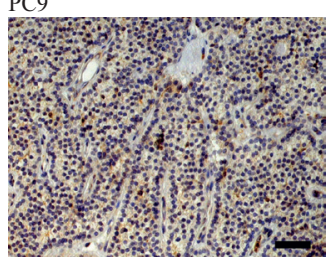

PC13
PC2

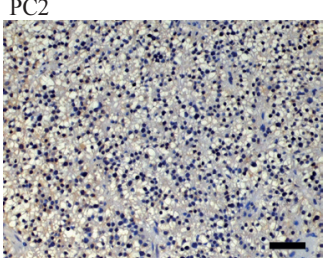

PC6

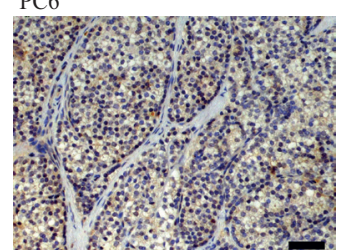

PC10

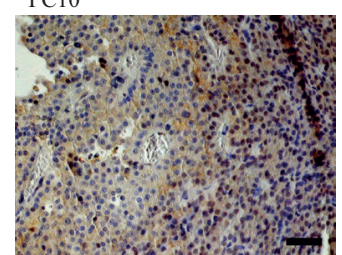

PC14

N2

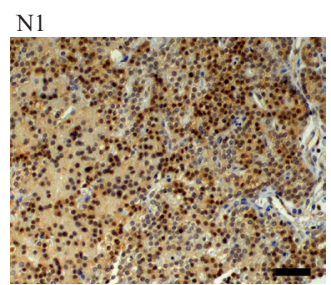

Normal kidney
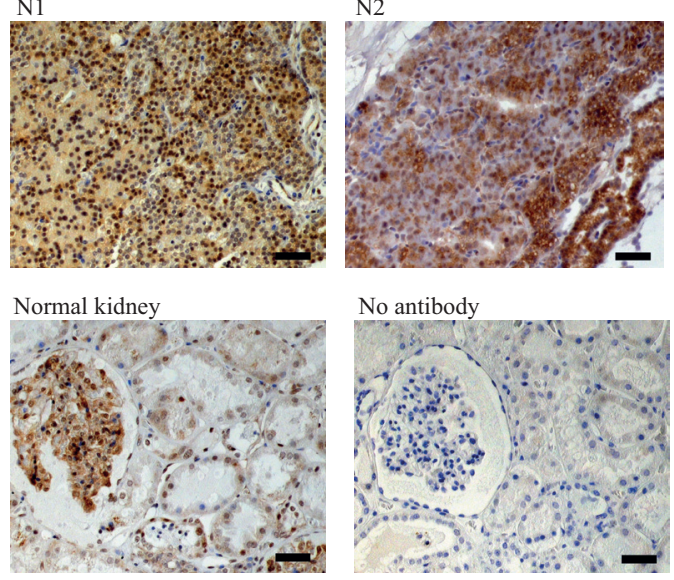
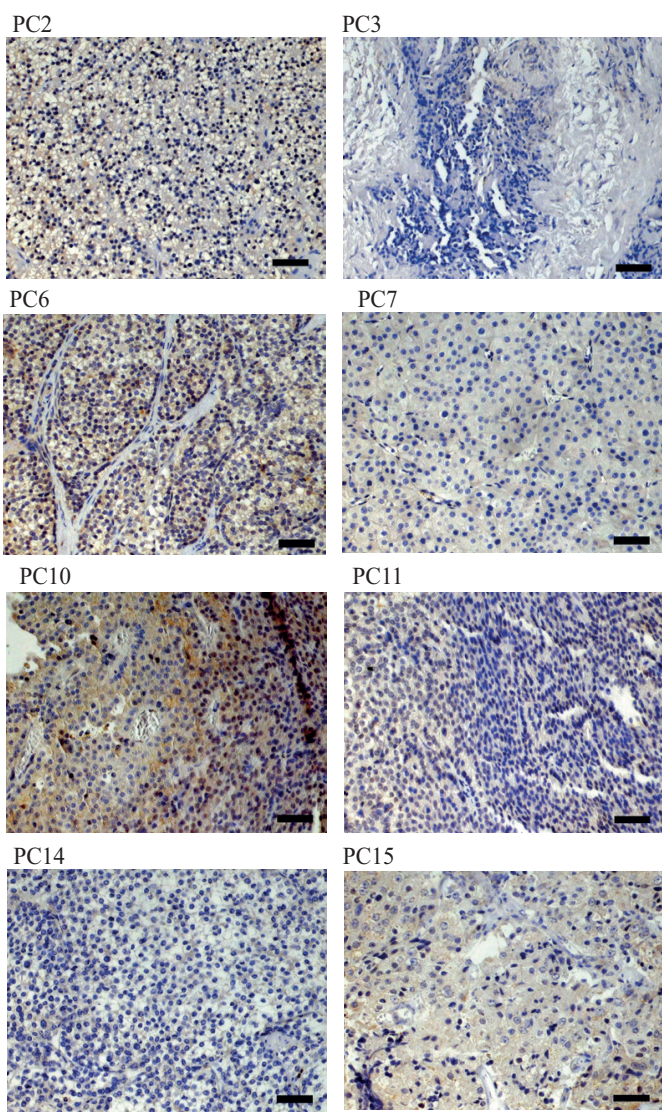
PC7

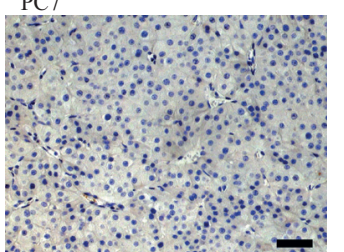

\section{PC11}

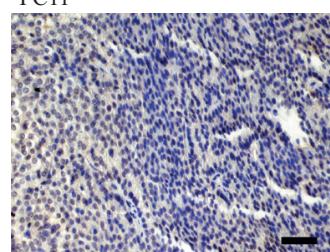

PC15

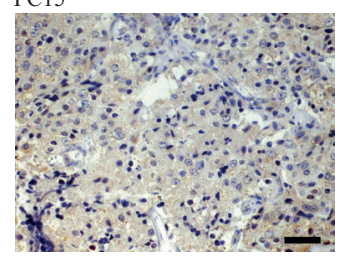

N3

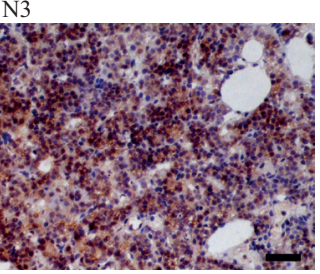

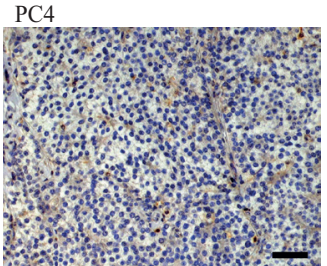

PC8

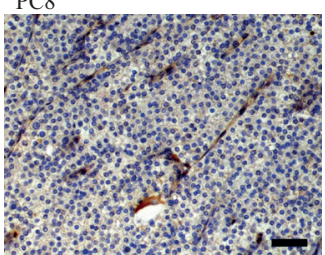

$\mathrm{PC} 12$
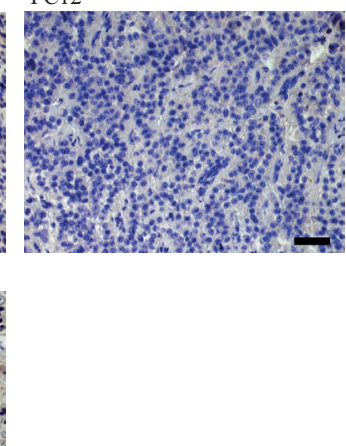

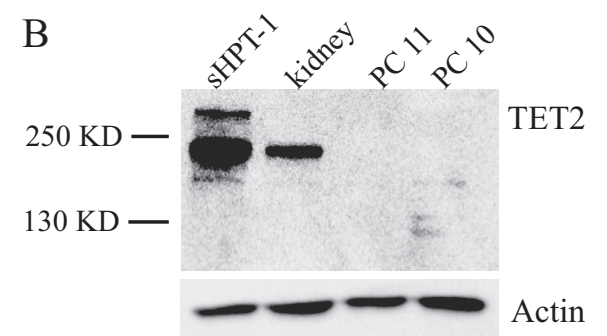

Figure 1

TET2 protein expression in PCs. (A) Immunohistochemical analysis of PCs ( $n=15)$ and three normal parathyroid specimens (N2 and N3 were frozen tissue sections). Normal kidney tissue was used as an additional positive control and was also analyzed without the primary TET2 antibody. Scale bar, $50 \mu \mathrm{m}$. (B) Western blotting analysis of TET2. The sHPT-1 cell line (Björklund et al. 2007), normal kidney tissue, PC10 and PC11 were analyzed. Isoforms of TET2 were observed in the sHPT-1 cell protein extract. 


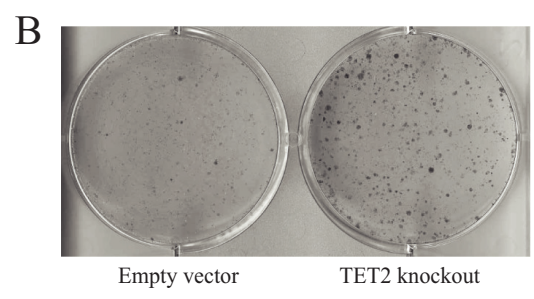

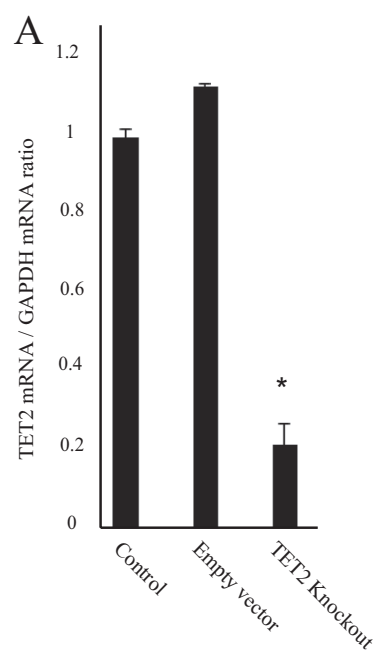

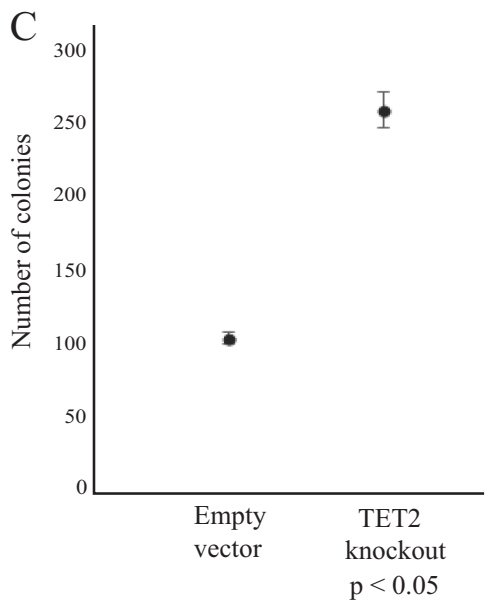

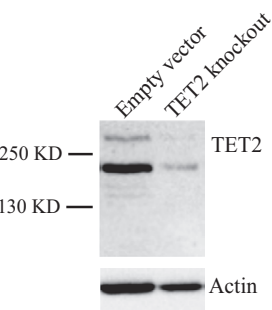

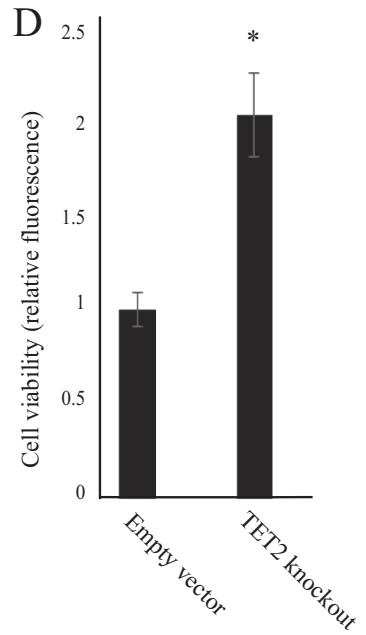

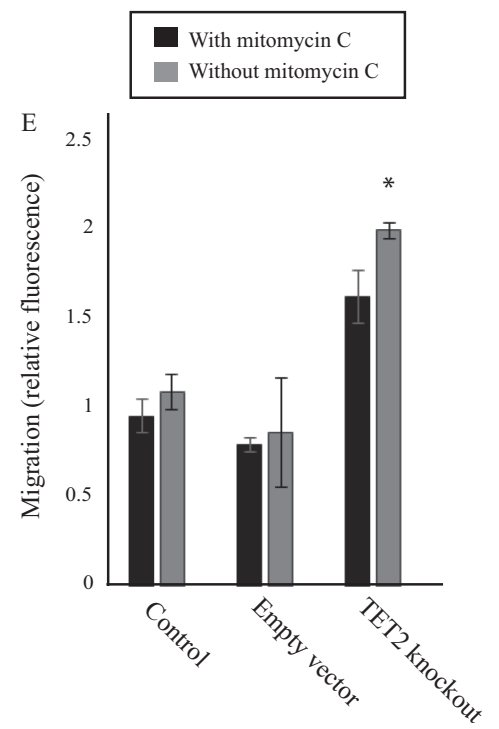

Figure 2

Colony formation assay, cell viability, and cell migration of the parathyroid cell line SHPT-1 after transfection of TET2 CRISPR double nickase plasmids. (A) Efficient knockout of TET2 was obtained at mRNA and protein level. (B) Colony formation assay. sHPT-1 cells transfected with TET2 CRISPR double nickase plasmids or control double nickase plasmids and selected after incubation with $0.5 \mu \mathrm{g} / \mathrm{mL}$ puromycin for 14 days. (C) Quantification of triplicates; empty vector $=105 \pm 4.1$ and TET2 $=260 \pm 12.1$. (D) Cell viability measured for $24 \mathrm{~h}, 2$ weeks after transfection and $0.5 \mu \mathrm{g} / \mathrm{mL}$ puromycin selection.

(E) Quantification of cell migration with $(P=0.06)$ and without the cell proliferation inhibitor mitomycin $C$. $* P<0.05$.

Interestingly, knockout of TET2 expression in sHPT-1 cells increased the migration velocity of the cells in vitro (Fig. 2E and Supplementary Fig. 2), although no effect on invasion capability in vitro of the cells was observed (data not shown). Increased cell migration was also observed in the presence of the cell proliferation inhibitor mitomycin C (Fig. 2E).

In order to investigate whether the cultured sHPT-1 cells changed in differentiation state during puromycin selection of TET2 knockout cells, PTH expression was monitored by immunofluorescence and immunohistochemistry. PTH expression was found to be reduced in TET2 knockout cells, but were still clearly detectable compared to that in untreated cells (Supplementary Fig. 3A and B). Reduced PTH protein expression seemed not to be caused by TET2 knockout as it was also observed in control transfected cells (not shown). PTH mRNA expression was also found to be reduced in control - and TET2 CRISPR transfected cells in comparison to untransfected cells as determined by quantitative RT-PCR analysis (not shown). The very low mRNA expression levels detected of the calcium sensing receptor (CASR) and the parathyroid-specific gene GCM2 were not affected by TET2 knockout (not shown).

Taken together, these results strongly suggest a cell growth regulatory and migratory role of TET2 in 
parathyroid cells and support function as a possible tumor suppressor gene in parathyroid tissue.

\section{DNA sequencing analysis revealed two common variants of TET2}

One possible explanation for the observed absence of TET2 expression in the PCs is the presence of missense mutation with mRNA or protein degradation. DNA sequencing of all TET2 coding exons in nine PCs, TET2 exon 11 in additional five PCs, and one blood sample revealed two common variants in exon 11 located in the catalytic region of TET2 protein containing the doublestranded beta-helix (DSBH) domain (Ko et al. 2010). Of these two variants, Ile1762Val occurred in three of 12 patients, in which one tumor was heterozygous. One blood sample was available and contained Ile1762Val. The second variant, His1778Arg was observed in both samples from one patient. Both these variants have been reported previously in acute myeloid leukemia (Weissmann et al. 2012), and also in a protein-coding genetic variation data set (Lek et al. 2016). According to these data, the Ile1762Val variant is frequent (allele frequency 0.2951) and predicted as a benign missense mutation using PolyPhen-2 (Adzhubei et al. 2010). The second variant, His1778Arg, predicted as a possibly damaging mutation with less frequency (allele frequency 0.04876, Lek et al. 2016). Potential effects on TET2 protein structure and function, and whether Ile1762Val and His1778Arg present genetic predispositions to PC is unknown. TET2 alterations were not detected in a whole-exome sequencing analysis of seven PCs (Yu et al. 2015).

\section{TET2 promoter is hypermethylated in parathyroid carcinomas}

We then turned our attention to epigenetic mechanisms. The TET2 gene upstream regulatory region contains a 1463 base pair long CpG island (Database of CpG islands, http://dbcat.cgm.ntu.edu.tw/) that possibly could be inactivated by DNA hypermethylation. We therefore measured the methylation level for 29 CpGs in 378 base pairs located in the promoter region of transcript TET2-201 that encodes the 2002 amino acid long TET2 polypeptide, by quantitative bisulfite pyrosequencing analysis (Supplementary Fig. 4). Figure 3A shows the detailed analysis of two PCs from the same patient (PC10 and PC11) in comparison to four parathyroid normal tissues. Significantly higher methylation levels (\%) were seen for $\mathrm{CpG}$ residues number $4-16$ for both carcinomas.
Interestingly, the methylation was higher for PC10, representing a metastasis after re-operation. Figure 3B shows the methylation levels (\%) of CpGs number 4-16 for all analyzed eleven PCs and the four normal tissues. A significantly higher methylation level was seen for the PCs, when comparing methylation level at each CpG site. All methylation data are presented in Supplementary Table 3. Low methylation levels of the 29 CpGs were found in normal kidney and in sHPT-1 parathyroid cells (Supplementary Table 3), consistent with the high level of TET2 expression that was observed by western blotting analysis (Fig. 1B). The parathyroid normal tissues showed overall somewhat higher methylation levels when compared to those of sHPT-1 and normal kidney (Supplementary Table 3) and there was no obvious difference in methylation level between the two parathyroid normal tissue specimens obtained from patients with HPT and hyperthyroidism, respectively.

It is very likely that the increased $\mathrm{CpG}$ methylation level of the TET2 promoter caused the observed downregulation of TET2 expression in the PCs. This was further supported by previous in vitro primary PC cell culture experiments (Svedlund et al. 2012). Treatment of the PC11 primary cell culture with the DNA methylation inhibitor 5-aza-2'-deoxycytidine (Aza) caused increased expression of the TET2 gene, whereas Aza treatment of sHPT-1 cells showed no effect (Fig. 3C). The induction was the same for a probe detecting transcripts TET2-201 and TET2-002 (both encoding 2002 amino acids) and for a probe detecting only TET2-001 (encoding 1165 amino acids), as measured by different TaqMan assays (not shown). All three transcriptional start sites are located in the CpG island.

\section{Discussion}

TET1 and TET2 play substantial roles in the development of cancer. Reduced expression of TET proteins and lower $5 \mathrm{hmClevels}$ are commonly observed in many cancer types. Inactivating mutations in TET2 is particularly common in hematological malignancies, and seem to cause aberrant expression of many genes by DNA hypermethylation at enhancers and transcription factor-binding sites, and less at CpG islands. TET1 seems to protect CpG island promoters from DNA methylation. Mutations in TET1 are not commonly observed, but epigenetic inactivation by DNA methylation was recently suggested to occur in multiple carcinomas and lymphomas (Rasmussen et al. 2015, Yamazaki et al. 2015, Li et al. 2016, Rasmussen \& Helin 2016).

Published by Bioscientifica Ltd. 
A
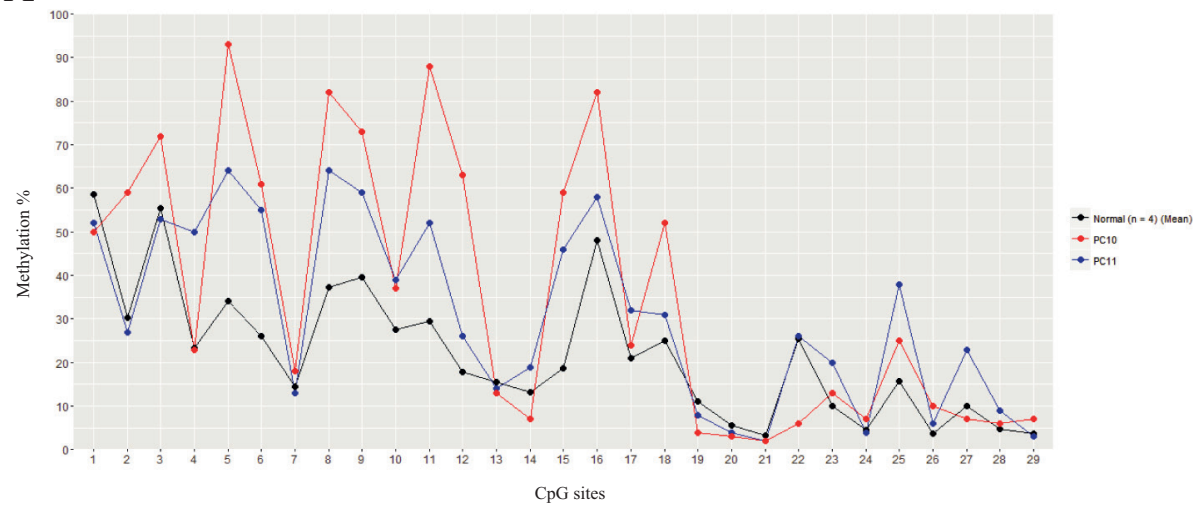

B
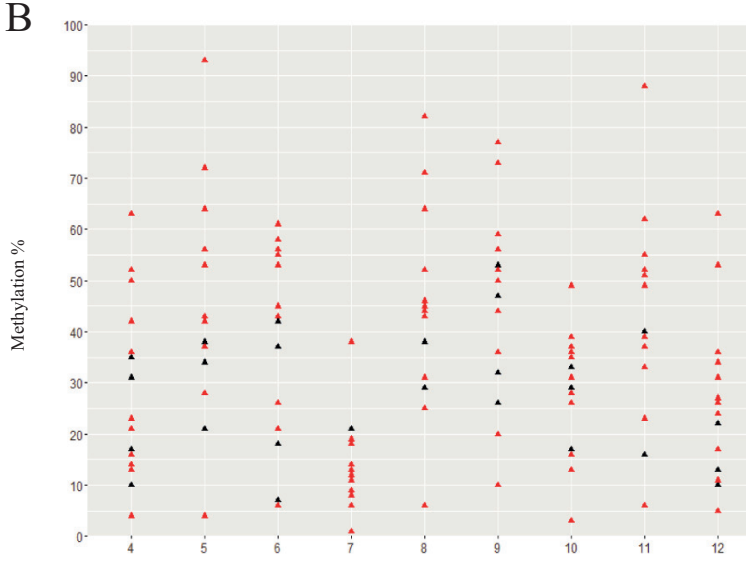

Figure 3

DNA methylation analysis of 29 CpGs by quantitative bisulfite pyrosequencing. (A) Mean methylation level (\%) of normal parathyroid tissues ( $n=4$ ) compared with the methylation level of two parathyroid carcinomas (PC10 and PC11) from the same patient. PC10 represents a metastasis after re-operation. Significantly higher methylation levels were seen for $\mathrm{CpG}$ residues number 4-16 for both carcinomas. (B) DNA methylation level (\%) of CpG residues number 4-16 in normal parathyroid tissue specimens (black; $n=4)$ and PCs (red; $n=11)$. A significant higher methylation level was seen for the PCs, when comparing methylation level at each CpG site. Supplementary Table 3 for all measurements. (C) Treatment of parathyroid cell line sHPT-1 and in vitro cultured primary parathyroid carcinoma cells (PC11) with $5 \mu \mathrm{M}$ 5-aza-2'-deoxycytidine (Aza). TET2/GAPDH mRNA expression ratio measured by real-time quantitative RT-PCR analysis. ${ }^{\star} P<0.05$.

Here, we demonstrate very low expression levels of the TET2 protein in all 15 analyzed PCs by immunohistochemistry and substantiated in 2 PCs by western blotting analysis. This may partly explain why we observed undetectable/low levels of $5 \mathrm{hmC}$ in all the PCs. TET1 expression was also found earlier to be perturbed in all PCs except for four tumors where overall positive staining was detected (Barazeghi et al. 2016). These four PCs were included here and thus showed very low expression of TET2. Thus, in common with various other cancers (Rasmussen \& Helin 2016) simultaneous decreased expression of TET1 and TET2 were observed for the majority of PCs analyzed here. Three PCs out of nine analyzed showed parafibromin expression (Supplementary Table 1) and no relation with the clinical data or TET2 promoter methylation levels were found (not shown). Similar to TET1 (Barazeghi et al. 2016), we could demonstrate a growth suppressive role for TET2 in parathyroid cells in vitro, supporting an important role also for TET2 in parathyroid tumorigenesis. Interestingly, we found that TET2 knockdown also interfered with the regulation of cell migration in vitro, resulting in increased migration. A role for TET2 in cell migration has also been reported in skin primary keratinocytes and suggested to drive a cancer phenotype in prostate cancer cells (Nickerson et al. 2016, Zhang et al. 2016). Interestingly, TET1 has been shown to affect cell migration and also invasion of gastric cancer cells (Pei et al. 2016).

In the absence of obvious inactivating mutations in TET2, we determined the methylation levels in a part of the TET2 CpG island by quantitative bisulfite pyrosequencing analysis. To our knowledge, this has not 
been done in previous TET2 investigations. Significantly, increased CpG methylation level was detected in the PCs in comparison to the normal parathyroid tissues. However, other inactivating mechanisms must also be involved; PC6 showed an obvious low methylation level throughout the region. Strong support for involvement of DNA hypermethylation in TET2 gene repression also includes the induction of TET2 by 5-aza-2'-deoxycytidine in the PC11 primary cell culture experiment. Interestingly, higher $\mathrm{CpG}$ methylation levels were observed in the metastasis compared to the primary tumor from the same patient (Fig. 3A). The re-operation was performed about 3 years later. This may be interpreted as selection of cell clone(s) with clearly repressed expression of TET2 during establishment and growth of the metastatic tumor cells.

\section{Supplementary data}

This is linked to the online version of the paper at http://dx.doi.org/10.1530/ ERC-17-0009.

\section{Declaration of interest}

The authors declare that there is no conflict of interest that could be perceived as prejudicing the impartiality of the research reported.

\section{Funding}

This work was supported by grants from The Swedish Cancer Society, Lions Fund for Cancer Research, and Erik, Karin o Gösta Selanders Stiftelse.

\section{Acknowledgments}

The authors thank Dr Peyman Björklund for the Aza-treated PC primary cells.

\section{References}

Abdel-Wahab O, Mullally A, Hedvat C, Garcia-Manero G, Patel J, Wadleigh M, Malinge S, Yao J, Kilpivaara O, Bhat R, et al. 2009 Genetic characterization of TET1, TET2, and TET3 alterations in myeloid malignancies. Blood 114 144-147. (doi:10.1182/blood2009-03-210039)

Adzhubei IA, Schmidt S, Peshkin L, Ramensky VE, Gerasimova A, Bork P, Kondrashov AS \& Sunyaev SR 2010 A method and server for predicting damaging missense mutations. Nature Methods 7 248-249. (doi:10.1038/nmeth0410-248)

Barazeghi E, Gill AJ, Sidhu S, Norlen O, Dina R, Palazzo FF, Hellman P, Stålberg P \& Westin G 2016 5-Hydroxymethylcytosine discriminates between parathyroid adenoma and carcinoma. Clinical Epigenetics $\mathbf{8}$ 31. (doi:10.1186/s13148-016-0197-2)

Björklund P, Åkerström G \& Westin G 2007 Activated beta-catenin in the novel human parathyroid tumor cell line sHPT-1. Biochemical and Biophysical Research Communications 352 532-536. (doi:10.1016/j.bbrc.2006.11.056)
Calabrese R, Valentini E, Ciccarone F, Guastafierro T, Bacalini MG, Ricigliano VA, Zampieri M, Annibali V, Mechelli R, Franceschi C, et al. 2014 TET2 gene expression and 5-hydroxymethylcytosine level in multiple sclerosis peripheral blood cells. Biochimica et Biophysica Acta 1842 1130-1136. (doi:10.1016/j.bbadis.2014.04.010) Cetani F, Banti C, Pardi E, Borsari S, Viacava P, Miccoli P, Torregrossa L, Basolo F, Pelizzo MR, Rugge M, et al. 2013 CDC73 mutational status and loss of parafibromin in the outcome of parathyroid cancer. Endocrine Connections 2 186-195. (doi:10.1530/EC-13-0046)

Chim CS, Wan TS, Fung TK \& Wong KF 2010 Methylation of TET2, CBL and CEBPA in Ph-negative myeloproliferative neoplasms. Journal of Clinical Pathology 63 942-946. (doi:10.1136/jcp.2010.080218)

DeLellis RA, Mazzaglia P \& Mangray S 2008 Primary hyperparathyroidism a current perspective. Archives of Pathology and Laboratory Medicine 132 1251-1262. (doi:10.1043/15432165(2008)132[1251:PHACP]2.0.CO;2)

Gill AJ 2014 Understanding the genetic basis of parathyroid carcinoma Endocrine Pathology 25 30-34. (doi:10.1007/s12022-013-9294-3)

Guarnieri V, Battista C, Muscarella LA, Bisceglia M, de Martino D, Baorda F, Maiello E, D'Agruma L, Chiodini I, Clemente C, et al. 2012 CDC73 mutations and parafibromin immunohistochemistry in parathyroid tumors: clinical correlations in a single-centre patient cohort. Cellular Oncology 35 411-422. (doi:10.1007/s13402-012-0100-x)

Haffner MC, Chaux A, Meeker AK, Esopi DM, Gerber J, Pellakuru LG, Toubaji A, Argani P, Iacobuzio-Donahue C, Nelson WG, et al. 2011 Global 5-hydroxymethylcytosine content is significantly reduced in tissue stem/progenitor cell compartments and in human cancers. Oncotarget 2 627-637. (doi:10.18632/oncotarget.316)

Huang Y \& Rao A 2014 Connections between TET proteins and aberrant DNA modification in cancer. Trends in Genetics $30464-474$. (doi:10.1016/j.tig.2014.07.005)

Iacobone M, Ruffolo C, Lumachi F \& Favia G 2005 Results of iterative surgery for persistent and recurrent parathyroid carcinoma. Langenbeck's Archives of Surgery 390 385-390. (doi:10.1007/s00423005-0555-6)

Ito S, D'Alessio AC, Taranova OV, Hong K, Sowers LC \& Zhang Y 2010 Role of Tet proteins in $5 \mathrm{mC}$ to $5 \mathrm{hmC}$ conversion, ES-cell selfrenewal and inner cell mass specification. Nature 466 1129-1133. (doi:10.1038/nature09303)

Jankowska AM, Szpurka H, Tiu RV, Makishima H, Afable M, Huh J, O’Keefe CL, Ganetzky R, McDevitt MA \& Maciejewski JP 2009 Loss of heterozygosity 4q24 and TET2 mutations associated with myelodysplastic/myeloproliferative neoplasms. Blood $\mathbf{1 1 3}$ 6403-6410. (doi:10.1182/blood-2009-02-205690)

Kan Z, Jaiswal BS, Stinson J, Janakiraman V, Bhatt D, Stern HM, Yue P, Haverty PM, Bourgon R, Zheng J, et al. 2010 Diverse somatic mutation patterns and pathway alterations in human cancers. Nature 466 869-873. (doi:10.1038/nature09208)

Kim YH, Pierscianek D, Mittelbronn M, Vital A, Mariani L, Hasselblatt M \& Ohgaki H 2011 TET2 promoter methylation in low-grade diffuse gliomas lacking IDH1/2 mutations. Journal of Clinical Pathology 64 850-852. (doi:10.1136/jclinpath-2011-200133)

Ko M, Huang Y, Jankowska AM, Pape UJ, Tahiliani M, Bandukwala HS, An J, Lamperti ED, Koh KP, Ganetzky R, et al. 2010 Impaired hydroxylation of 5-methylcytosine in myeloid cancers with mutant TET2. Nature 468 839-843. (doi:10.1038/nature09586)

Kudo Y, Tateishi K, Yamamoto K, Yamamoto S, Asaoka Y, Ijichi H, Nagae G, Yoshida H, Aburatani H \& Koike K 2012 Loss of 5-hydroxymethylcytosine is accompanied with malignant cellular transformation. Cancer Science 103 670-676. (doi:10.1111/j.1349-7006.2012.02213.x)

Lek M, Karczewski KJ, Minikel EV, Samocha KE, Banks E, Fennell T, O'Donnell-Luria A, Ware JS, Hill AJ, Cummings BB, et al. 2016 Analysis of protein-coding genetic variation in 60,706 humans. Nature 536 285-291. (doi:10.1038/nature19057)
(C) 2017 Society for Endocrinology Printed in Great Britain
Published by Bioscientifica Ltd 
Li L, Li C, Mao H, Du Z, Chan WY, Murray P, Luo B, Chan AT, Mok TS, Chan FK, et al. 2016 Epigenetic inactivation of the CpG demethylase TET1 as a DNA methylation feedback loop in human cancers. Scientific Reports 6 26591. (doi:10.1038/srep26591)

Lian CG, Xu Y, Ceol C, Wu F, Larson A, Dresser K, Xu W, Tan L, Hu Y, Zhan Q, et al. 2012 Loss of 5-hydroxymethylcytosine is an epigenetic hallmark of melanoma. Cell 150 1135-1146. (doi:10.1016/j.cell.2012.07.033)

Musialik E, Bujko M, Wypych A, Matysiak M \& Siedlecki JA 2014 TET2 promoter DNA methylation and expression analysis in pediatric B-cell acute lymphoblastic leukemia. Hematology Reports 65333. (doi:10.4081/hr.2014.5333)

Nickerson ML, Das S, Im KM, Turan S, Berndt SI, Li H, Lou H, Brodie SA, Billaud JN, Zhang T, et al. 2016 TET2 binds the androgen receptor and loss is associated with prostate cancer. Oncogene 36 2172-2183. (doi:10.1038/onc.2016.376)

Pei YF, Tao R, Li JF, Su LP, Yu BQ, Wu XY, Yan M, Gu QL, Zhu ZG \& Liu BY 2016 TET1 inhibits gastric cancer growth and metastasis by PTEN demethylation and re-expression. Oncotarget 7 31322-31335. (doi:10.18632/oncotarget.8900)

Rasmussen KD \& Helin K 2016 Role of TET enzymes in DNA methylation, development, and cancer. Genes and Development 30 733-750. (doi:10.1101/gad.276568.115)

Rasmussen KD, Jia G, Johansen JV, Pedersen MT, Rapin N, Bagger FO, Porse BT, Bernard OA, Christensen J \& Helin K 2015 Loss of TET2 in hematopoietic cells leads to DNA hypermethylation of active enhancers and induction of leukemogenesis. Genes and Development 29 910-922. (doi:10.1101/gad.260174.115)

Scourzic L, Mouly E \& Bernard OA 2015 TET proteins and the control of cytosine demethylation in cancer. Genome Medicine 79. (doi:10.1186/s13073-015-0134-6)

Sharretts JM \& Simonds WF 2010 Clinical and molecular genetics of parathyroid neoplasms. Best Practice and Research: Clinical Endocrinology and Metabolism 24 491-502. (doi:10.1016/j. beem.2010.01.003)

Svedlund J, Auren M, Sundstrom M, Dralle H, Åkerström G, Björklund P \& Westin G 2010 Aberrant WNT/beta-catenin signaling in parathyroid carcinoma. Molecular Cancer 9 294. (doi:10.1186/14764598-9-294)
Svedlund J, Koskinen Edblom S, Marquez VE, Åkerström G, Björklund P \& Westin G 2012 Hypermethylated in cancer 1 (HIC1), a tumor suppressor gene epigenetically deregulated in hyperparathyroid tumors by histone H3 lysine modification. Journal of Clinical Endocrinology and Metabolism 97 E1307-E1315. (doi:10.1210/jc.2011-3136)

Tahiliani M, Koh KP, Shen Y, Pastor WA, Bandukwala H, Brudno Y, Agarwal S, Iyer LM, Liu DR, Aravind L, et al. 2009 Conversion of 5-methylcytosine to 5-hydroxymethylcytosine in mammalian DNA by MLL partner TET1. Science 324 930-935. (doi:10.1126/ science.1170116)

Tan MH, Morrison C, Wang P, Yang X, Haven CJ, Zhang C, Zhao P, Tretiakova MS, Korpi-Hyovalti E, Burgess JR, et al. 2004 Loss of parafibromin immunoreactivity is a distinguishing feature of parathyroid carcinoma. Clinical Cancer Research $106629-6637$. (doi:10.1158/1078-0432.CCR-04-0493)

Weissmann S, Alpermann T, Grossmann V, Kowarsch A, Nadarajah N, Eder C, Dicker F, Fasan A, Haferlach C, Haferlach T, et al. 2012 Landscape of TET2 mutations in acute myeloid leukemia. Leukemia 26 934-942. (doi:10.1038/leu.2011.326)

Westin G 2016 Molecular genetics and epigenetics of nonfamilial (sporadic) parathyroid tumours. Journal of Internal Medicine $\mathbf{2 8 0}$ 551-558. (doi:10.1111/joim.12458)

Yamazaki J, Jelinek J, Lu Y, Cesaroni M, Madzo J, Neumann F, He R, Taby R, Vasanthakumar A, Macrae T, et al. 2015 TET2 mutations affect non-CpG island DNA methylation at enhancers and transcription factor-binding sites in chronic myelomonocytic leukemia. Cancer Research 75 2833-2843. (doi:10.1158/0008-5472.CAN-14-0739)

Yu W, McPherson JR, Stevenson M, van Eijk R, Heng HL, Newey P, Gan A, Ruano D, Huang D, Poon SL, et al. 2015 Whole-exome sequencing studies of parathyroid carcinomas reveal novel PRUNE2 mutations, distinctive mutational spectra related to APOBEC-catalyzed DNA mutagenesis and mutational enrichment in kinases associated with cell migration and invasion. Journal of Clinical Endocrinology and Metabolism 100 E360-E364. (doi:10.1210/ jc.2014-3238)

Zhang J, Yang C, Wang C, Liu D, Lao G, Liang Y, Sun K, Luo H, Tan Q, Ren M, et al. 2016 AGE-induced keratinocyte MMP-9 expression is linked to TET2-mediated CpG demethylation. Wound Repair and Regeneration 24 489-500. (doi:10.1111/wrr.12426)

Received in final form 31 March 2017

Accepted 25 April 2017
(C) 2017 Society for Endocrinology Printed in Great Britain
Published by Bioscientifica Ltd. 